\title{
Optimum Pre-load of Surface Acoustic Wave Motor
}

\author{
Minoru Kurosawa, Masakazu Takahashi and Toshiro Higuchi \\ Dept. of Precision Machinery Engineering, Graduate School of Engineering, The University of Tokyo \\ 7-3-1 Hongo, Bunkyo-ku, Tokyo 113, JAPAN, e-mail: mkur@ pe.u-tokyo.ac.jp
}

\begin{abstract}
We have examined optimum pressing force, namely, pre-load for a slider to obtain superior operation condition of a surface acoustic wave motor. We used steel balls for sliders. With a permanent magnet the pre-load was controlled. The steel balls that we used were $0.5,1$ and $2 \mathrm{~mm}$ diameter to change contact conditions such as contact pressure, contact area and deformation of a stator and the slider. The stator transducer was lithium niobate 128 degrees Y-rotated X-propagation substrate. The driving frequency of the Rayleigh wave was about $10 \mathrm{MHz}$. As a result, the deformation of the stator and the slider by the pre-load should be half of the particle vibration amplitude. This condition was independent to the ball diameter and particle vibration amplitude. It was achieved that the output thrust force per square mm was $50 \mathrm{~N}$ and the maximum speed was $0.8 \mathrm{~m} / \mathrm{sec}$. The surface acoustic wave motor must have high potential to be a large output force, high speed, quick response, long traveling distance and low in profile micro linear actuator.
\end{abstract}

\section{INTRODUCTION}

We have demonstrated the operation of the friction drive surface acoustic wave motor[1]. The important point was the contact between a slider and a stator. For friction drive with nano meter order high frequency vibration, the high contact pressure such as $100 \mathrm{MPa}$ was required. However, the performance was not sufficient for an actual actuator. Hence, operation conditions were investigated in detail.

\section{EXPERIMENTAL SET UP}

A stator transducer for the experiments is same as previous paper[1]. A piezoelectric wafer was 128 degrees yrotated x-propagation $\mathrm{LiNbO}_{3}$. Two IDT (interdigital transducer) were arranged on a 3 inches wafer as shown in Fig. 1. The IDT pitch was $400 \mu \mathrm{m}$ and the electrodes strip width was $100 \mu \mathrm{m}$. The electrode strip was 10 pairs for each transducer. The driving frequency was 9.6 MHz. The normal direction vibration amplitude of the surface particle was 16 nano meter at driving voltage of $150 \mathrm{~V}$. The tangential direction vibration velocity was $0.7 \mathrm{~m} / \mathrm{sec}$.

A slider of this motor was small steal ball. In order to increase a pre-load, namely the pressing force of the slider to the stator, a permanent magnet was put beneath the wafer. The pre-load was changed by spacer thickness between the magnet and the wafer. Owing to the effect of the magnetization of the steal ball, the slider moved without rotation. The magnet was $5 \times 5 \times 25 \mathrm{~mm}^{3}$ Neodymium permanent magnet which was magnetized thick direction. The uniformity of the magnetic attractive force was confirmed within the operational area of the motor.

The attraction force between the permanent magnet and the steel balls of $0.5,1.0$ and $2.0 \mathrm{~mm}$ diameters was measured with an electric balance. The gap between the magnet and the ball was changed from $1 \mathrm{~mm}$ (thickness of the wafer) to 8.5 $\mathrm{mm}$ using several spacers. From the attractive force, the contact pressure distribution between the stator $\left(\mathrm{LiNbO}_{3}\right.$ wafer) and the steel balls are calculated using the Hertz contact theorem. At the center of the contact region, the pressure become maximum. The maximum contact pressures are shown in Fig. 2. The contact pressure was able to change up to 400 MPa for $0.5 \mathrm{~mm}$ diameter ball and up to $600 \mathrm{MPa}$ for $2.0 \mathrm{~mm}$ diameter ball. In the previous paper, the contact pressure was around $100 \mathrm{MPa}[1]$.

Because of the elasticity of the materials, the contact area of the slider ball is finite. The slider and the stator deform as illustrated in Fig. 3. The contact radius is able to evaluate with the Hertz contact theorem approximately. The actual contact

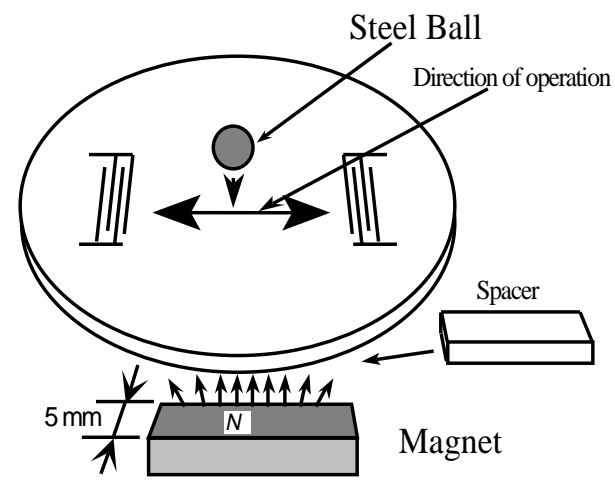

Fig. 1 Experimental set up. 


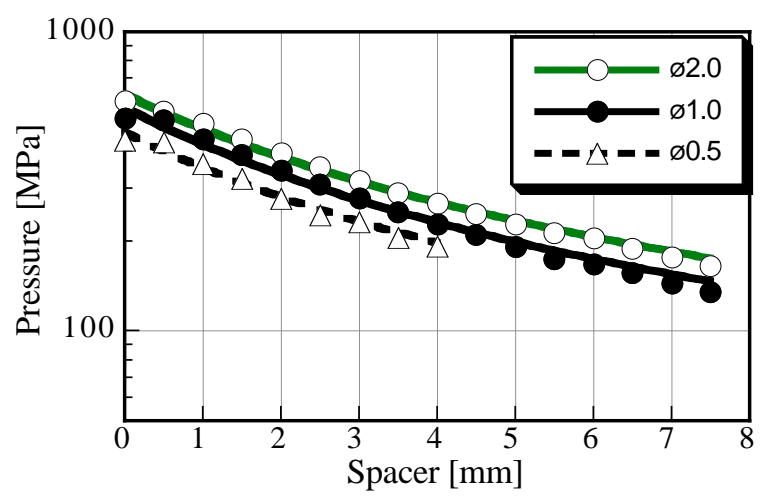

Fig. 2 Maximum contact pressure of the ball sliders.

radius was several micro meter at most when the steel ball sliders were put on the stator with attractive force by the permanent magnet. For example, the contact radius, the depression and the maximum contact pressure were about $3 \mu \mathrm{m}, 9 \mathrm{~nm}$ and $390 \mathrm{MPa}$ when the ball diameter was $1 \mathrm{~mm}$ and the spacer thickness was $1.5 \mathrm{~mm}$. It should be pointed out that the deformation is almost same order with the stator vibration deformation.

\section{TRANSIENT RESPONSE IN SHORT TIME DRIVE}

For optimum pre-load condition, the high speed and the large thrust should compromise. In the case of the light preload, the stationary speed is high but the thrust is tiny. On the contrary, the high pre-load condition, they are vise verse. At the excessive pre-load, a slider never moves any more. The high speed and the large thrust is trade off. Moderate pre-load condition should be investigated to pull out the performance in itself.

From the transient response of ultrasonic motor, we can estimate a performance such as thrust force and stationary speed. If the motor has high thrust output force, or the driving period is long enough, the traveling distance is proportional to the driving period. On the other hand, if the motor has low thrust output force, or the driving period is short, the traveling

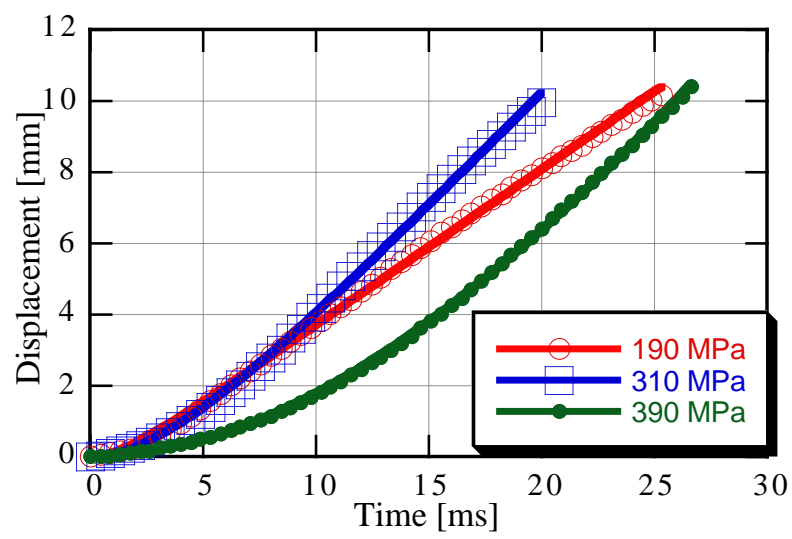

Fig. 4 Transient displacement of $1 \mathrm{~mm}$ ball slider.

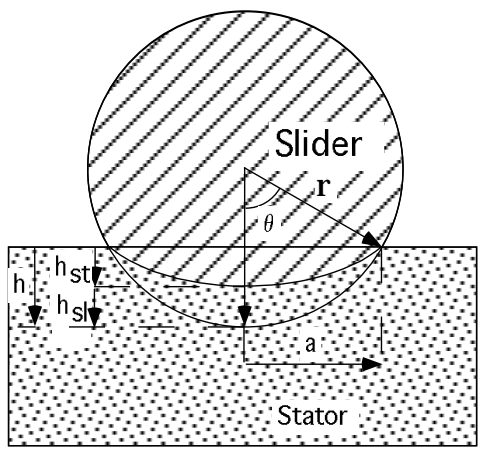

Fig. 3 Deformation of the slider and the stator.

distance is proportional to the square of the driving duration. From the measurement of the traveling distance of the middle short duration drive, therefore, both of the thrust and the stationary speed will be estimated. In other words, the traveling distance of the slider will become maximum at the optimum pre-load in an appropriate short time drive.

For example, the transient responses of the slider measured with a high speed video camera and an image processing equipment are shown in Fig. 4. From the differential of the displacement data, the transient speed curves were obtained as indicated in Fig. 5. From these data, it is understood that the transition region was around $3 \mathrm{msec}$. We decided, therefore, to measure the displacement in $3 \mathrm{msec}$ drive about various operation conditions.

At the driving voltage of $180 \mathrm{~V}$, the displacement of the slider in $3 \mathrm{msec}$ drive were measured. The driving performance has been improved significantly comparison with the previous result as shown in Fig. 6. The sliders were 0.5, 1 and $2 \mathrm{~mm}$ diameters. The maximum displacement conditions depended on the diameter. For the $2 \mathrm{~mm}$ diameter ball, the optimum pre-load was about $270 \mathrm{MPa}$. However, it was 350 MPa for the $1 \mathrm{~mm}$ diameter ball and seemed to be much higher for the $0.5 \mathrm{~mm}$ diameter ball. The optimum pressure depended on the geometry of the sliders.

On the other hand, the depression of the sliders gave a

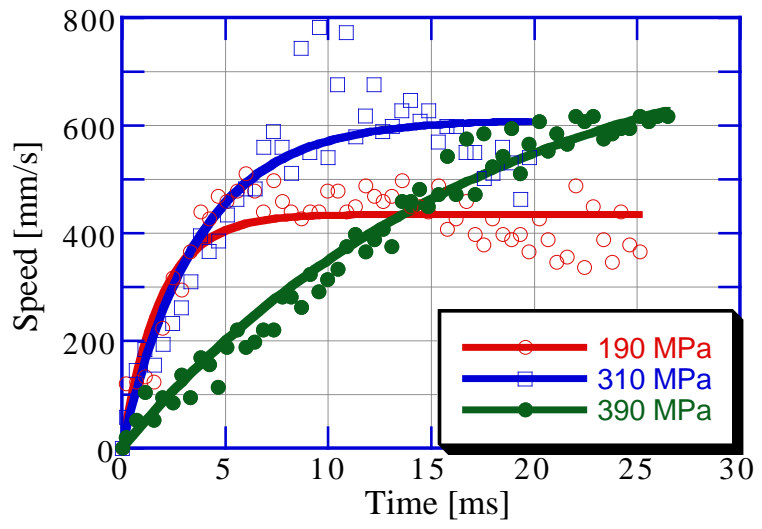

Fig. 5 Transient response of the $1 \mathrm{~mm}$ ball slider. 


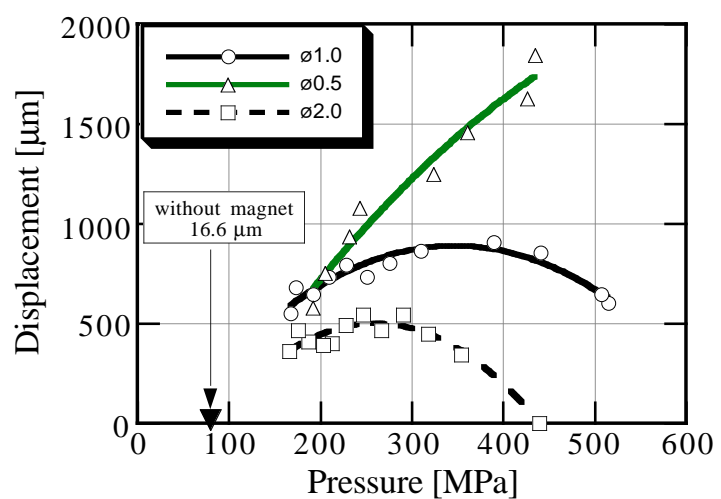

Fig. 6 Displacement of the slider with $3 \mathrm{msec}$ drive aginst contact pressure.

good result. Fig. 7 indicates the displacement in $3 \mathrm{msec}$ drive as a function of the depression due to the pre-load. The optimum depression of the $1 \mathrm{~mm}$ and $2 \mathrm{~mm}$ ball sliders were the same around $9 \mathrm{~nm}$. The normal direction vibration displacement of the stator at $180 \mathrm{~V}$ driving voltage was 19 $\mathrm{nm}$. Hence the optimum depression of the slider was almost half of the particle vibration displacement of the surface wave.

To confirm the optimum depression condition at the different vibration amplitude, we estimated in the same way at the different driving voltage of $120 \mathrm{~V}$ and $60 \mathrm{~V}$ using $0.5 \mathrm{~mm}$ and $1 \mathrm{~mm}$ diameter balls. The results of Fig. 8 indicates that the half of the vibration displacement is optimum. The optimum depression was about $6 \mathrm{~nm}$ for $120 \mathrm{~V}$ and was about 3 $\mathrm{nm}$ for $60 \mathrm{~V}$. They were also the half of the vibration displacement. It is concluded that to obtain large thrust and high speed, namely quick response, the pre-load should be adjusted that the depression is the half of the vibration displacement.

\section{THRESHOLD AND STEADY SPEED}

Usually, an ultrasonic motor has dead zone at low driving voltage that a slider dose not move. The threshold driving voltage or vibration amplitude seems to depend on the pre-

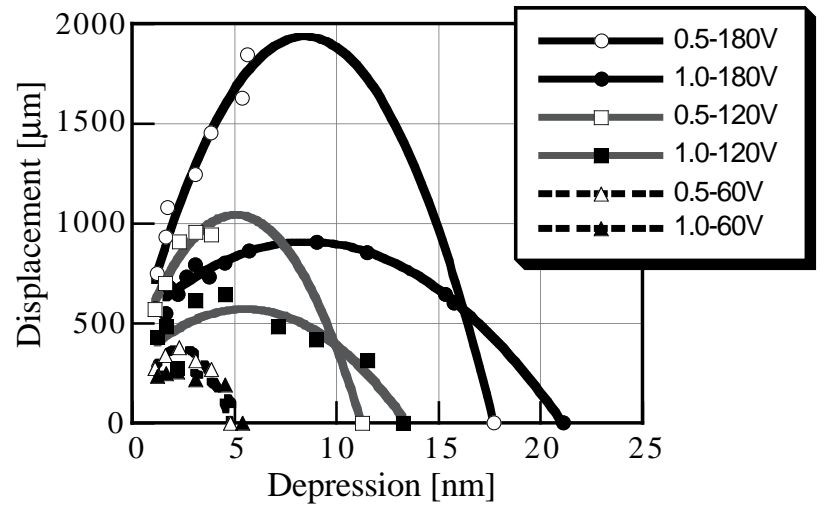

Fig. 8 Displacement of the sliders by $3 \mathrm{msec}$ drive with variation of voltage.

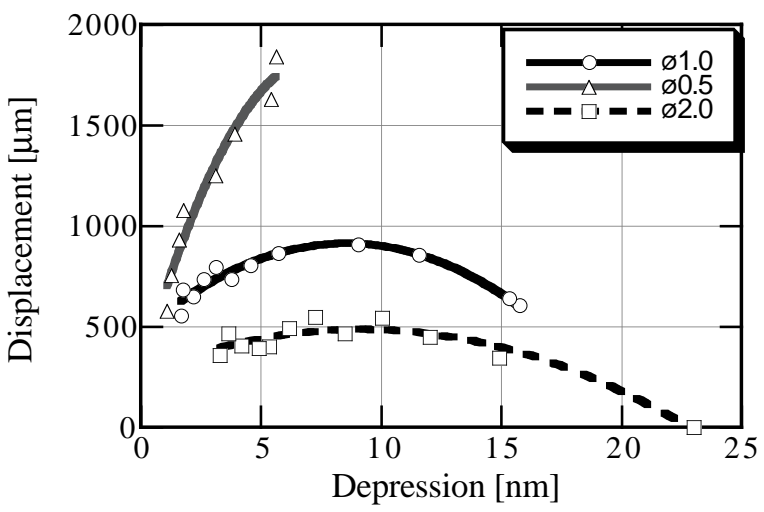

Fig. 7 Displacement of the slider with $3 \mathrm{msec}$ drive against a depression.

load. However, the quantitative relation between the pre-load and the threshold vibration amplitude have not been made clear.

Threshold driving voltage was measured against maximum contact pressure about the three different diameter balls. The threshold voltage depended on both the pressure and the diameter. However, concern with the depression of the sliders, the threshold voltages were independent to the ball diameter as recognized from Fig. 9. The threshold vibration displacement was almost the same as the depression of the sliders. For example, when the depression was $10 \mathrm{~nm}$, the threshold voltage was about $100 \mathrm{~V}$, namely $10 \mathrm{~nm}$ vibration displacement amplitude. It was found that at the low vibration amplitude, the threshold was slightly higher than depression and that at the high vibration amplitude, the threshold was slightly lower than depression. It might be the influence of the roughness of contact surfaces.

The stationary slider speed was independent to the ball diameters. In this experiment, the driving voltage was $120 \mathrm{~V}$ and $180 \mathrm{~V}$. The slider speed depended on only the vibration displacement amplitude at the same depression. This means that the depression is the factor that the stationary speed is settled.

Figure 10 indicates the ratio of the slider speed to the

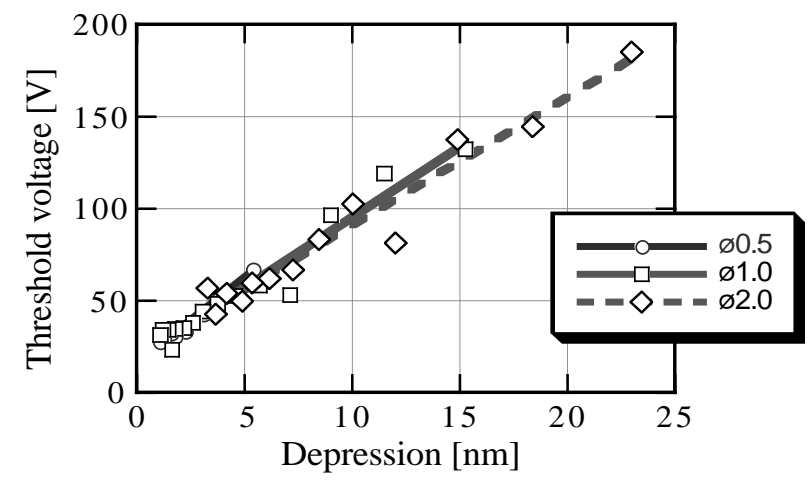

Fig. 9 Threshold driving voltage for operation. 


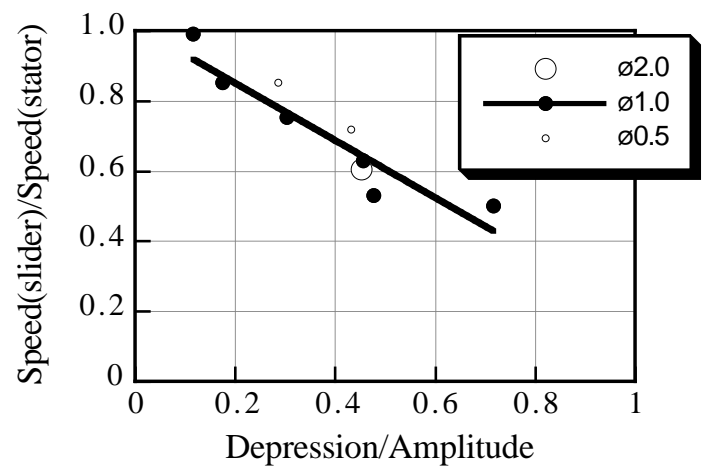

Fig. 10 Ratio of the motor speed to the vibation as a function of the depression.

tangential vibration velocity as a function of the ratio of the depression to the normal vibration displacement. Namely, the speed and the depression are normalized by the vibration amplitude of the stator surface particles for the convenience of comparison between the different driving conditions. The slider speed was settled by the ratio of the depression to the normal vibration displacement.

\section{OUTPUT FORCE OF THE FRICTION DRIVE}

To estimate the output force of the surface acoustic wave motor, available thrust and optimum condition of operation were investigated. In the experiment carried out in the section 3 , the optimum condition was a balance of the acceleration and the stationary speed. That was a simple way and appropriate to know roughly. However, for the quantitative evaluation, the dynamic response should be measured. For this purpose, the transient motion of the sliders were measured using the high speed camera and the image processor unit. This method was effective to measured the dynamic response of the motor, but it was not so efficient. It took several hours for the image processing so that the measured conditions were limited.

The speed of the slider was calculated from the differential of the displacement between the frames. Figures 9 and 10 are

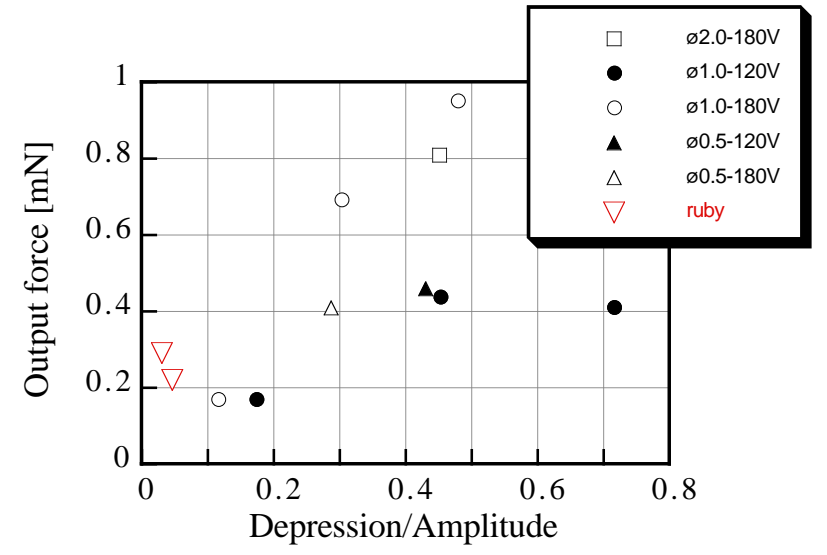

Fig. 11 Output force. the result about $1 \mathrm{~mm}$ diameter ball. From these responses, the stationary speed, rise up time and maximum acceleration were estimated. The three pre-load values were $390 \mathrm{MPa}, 310 \mathrm{MPa}$ and $190 \mathrm{MPa}$. The pre-load of $390 \mathrm{MPa}$ was the optimum condition from the $3 \mathrm{msec}$ drive at $180 \mathrm{~V}$. The rise up time was shortest at this pre-load, thus the thrust was maximum of 0.95 $\mathrm{mN}$. On the contrary, the stationary speed was maximum of $800 \mathrm{~mm} / \mathrm{sec}$ at the pre-load of $190 \mathrm{MPa}$.

The output force of the several driving conditions are plotted in Fig. 11 as a function of the depression ratio to the normal vibration displacement. At the depression ratio of around 0.5 , the output force was maximum. But the value of the force depended on the ball diameter because the contact area and the pressure were different. The thrust divided by the contact area is shown in Fig. 12. In the case of the $0.5 \mathrm{~mm}$ diameter ball, the thrust density was about $50 \mathrm{~N} / \mathrm{mm}^{2}$. This was lager than the $1 \mathrm{~mm}$ diameter ball because of the difference of the contact pressure. Namely, the smaller ball require high contact pressure for the same deformation. From the view point of the acceleration, the smaller ball was favorable. The maximum acceleration was $900 \mathrm{~m} / \mathrm{sec}^{2}$.

\section{CONCLUSION}

We have succeeded in improvement for friction drive conditions of the surface acoustic wave motor. The important point was the deformation ration of the slider and the stator against the normal vibration displacement. It is worth of notice that the thrust density was $50 \mathrm{~N} / \mathrm{mm}^{2}$, the maximum acceleration was $900 \mathrm{~m} / \mathrm{sec}^{2}$ and the maximum speed was $0.8 \mathrm{~m} / \mathrm{sec}$. We found out the availability of the surface acoustic wave motor for a superior linear micro actuator we have ever known.

\section{ACKNOWLEDGMENT}

This work was supported by the Grant-in-aid for general scientific research of the Ministry of Education, Science, Sports and Culture.

\section{REFERENCES}

[1]M. Kurosawa, M. Takhashi and T. Higuchi, "Ultrasonic linear motor using surface acoustic waves," IEEE Trans. on UFFC, vol. 43, no. 5, pp.901-906(1996).

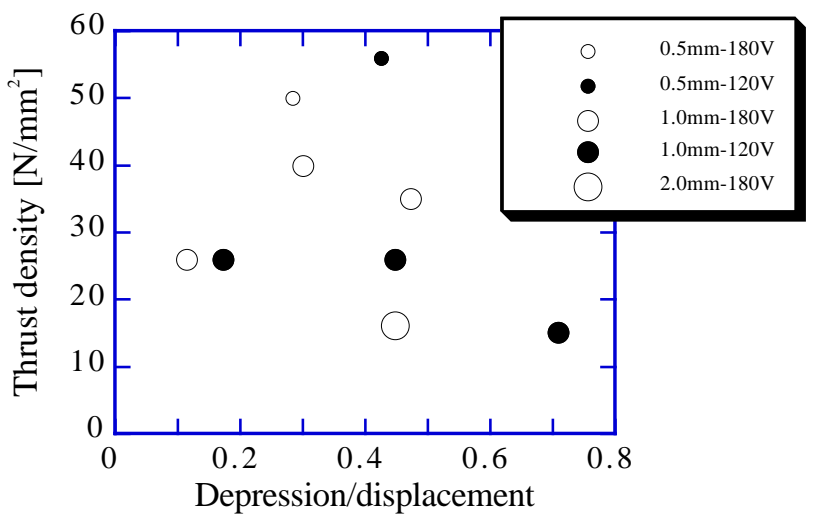

Fig. 12 Output force density of the ball sliders as a function of the depression/displacement ratio. 